\title{
Suffer the children
}

I $\mathrm{n}$ a troubled country such as the Kingdom of Swaziland, where $31 \%$ of adults are HIV-positive and the unemployment rate is $47 \%$, no one is more vulnerable than the children.

One marker is the number of orphans within the nation, an estimated 101000 , or $8.4 \%$ of the total population. Of those, about 69000 have been orphaned because of HIV (www.hopechest.org/swaziland/).

Despite the staggering numbers, orphanages do not exist in Swaziland. Tradition demands that orphans be taken in by the extended family. But given the ravages of HIV/AIDS, the extended family may mean rather distant relatives. And often these people are ill themselves, or very poor. The burden of another child can be overwhelming.

"Almost every family has a child who is not theirs," says Zelda Nhlabatsi, executive director of the Family Life Association of Swaziland, a nongovernmental association that operates four family planning and HIV/ AIDS clinics.

Undoubtedly, some of these children are well cared for by their extended family. But others have definitely fallen through the cracks as evidenced by high rates of abuse and teen pregnancy, and existing roadblocks to treating children with HIV.

According to UNAIDS, of the 21780 Swazi children living with HIV in 2011, only 53\% who need antiretroviral therapy (ART) receive it. In comparison, $80 \%$ of adults who need ART receive it (www.unaids.org/en/dataanalysis/know yourresponse/countryprogressreports /2012countries/ce_SZ_Narrative_Report [1].pdf).

Médecins sans Frontières (MSF), which has been working to expand testing and treatment in Swaziland since 2007, contends that the majority of children infected with HIV who are still not on treatment are in that position because of poorly managed follow-up of at-risk kids, including orphans (www.doctors withoutborders.org/publications/reports

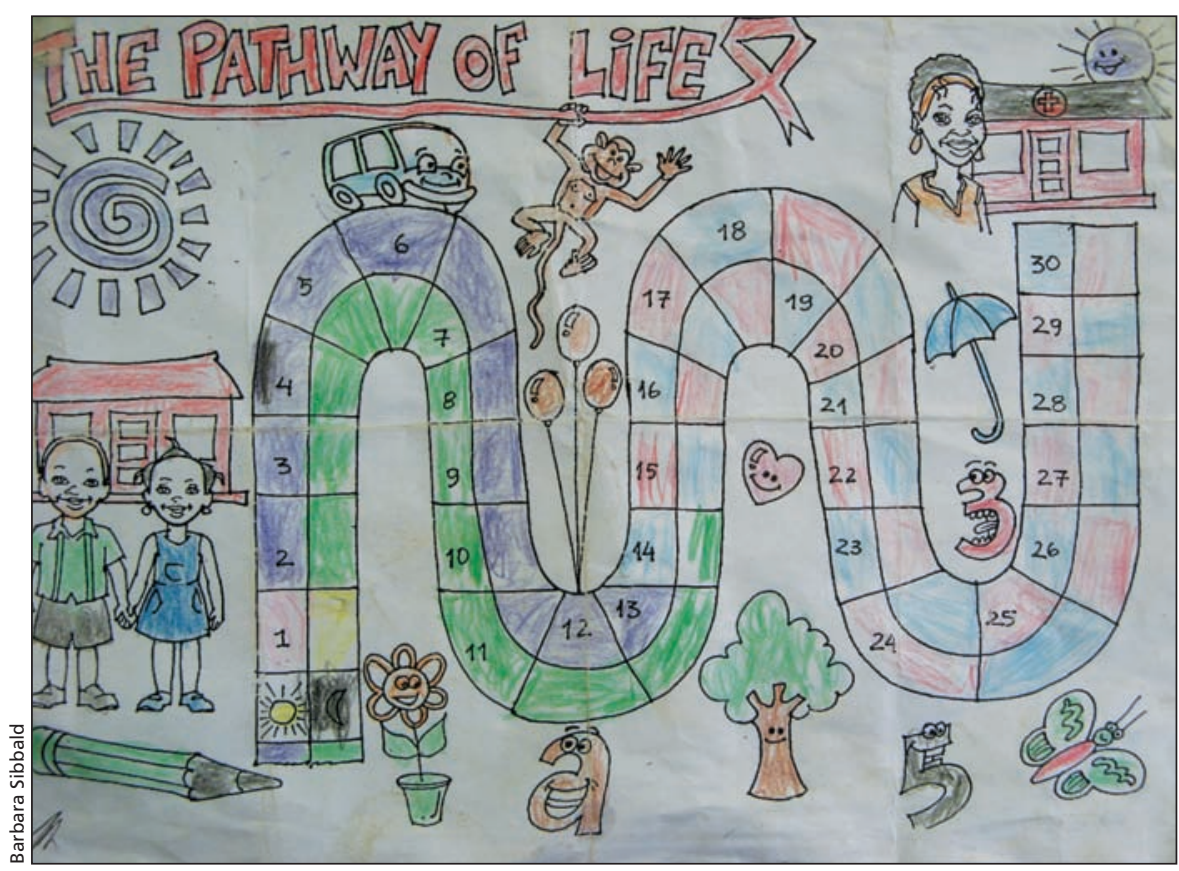

It's difficult to ensure that orphans and other vulnerable children who are HIV-positive are taking their medication. Médecins sans Frontières clinic staff at the Mankayane Government Hospital teach children to colour in the squares, morning and evening, when they take their antiretrovirals.

/2010/MSF-Swaziland-Treating-a-dual -epidemic-2010.pdf).

"Some don't get enough care or support from their family," says Mumcy Dlamini, an "expert client" for MSF at the Hluti clinic in the remote region of Shiselweni. "They [relatives] will send a child alone to get medications. A child forgets how to take them, then defaults."

On other occasions, a relative will abandon the child and go to work, says Fexon Ncube, a registered nurse and supervisor for the Matsayeni health zone in Shiselweni. When a child arrives alone, there are often problems, he adds. "The big challenge with kids is disclosure. We don't know what drugs they have taken. They don't know their medical history."

"It's very tough," Ncube notes. "We don't know how to help these children."

In general, HIV-positive teenagers present a challenge, says Raquel Gordon, the senior registered nurse at Hluti clinic. Often, they can't comprehend how they got infected. "They say they are virgins and we try to explain it (mother-to-child transmission), but they get angry and stop taking their medication. If they're a virgin, they feel they didn't do anything wrong. I don't know how we can help them. Our fear is they'll start infecting each other. And of course, there's a high teen pregnancy rate."

About a quarter of pregnant women are teenagers, says Nhlabatsi. "HIV affects $10 \%$ of girl youths and $2 \%$ of male youths. We also get children with STIs [sexually transmitted infections]."

"Girls are vulnerable; they're afraid to say no," Nhlabatsi explains. "Lots of them are orphans and will exchange sex for school fees or food."

Education is state-sponsored but only free until children start grade four. After that, they must pay 200 to 300 lilangeni (\$23-\$34) for uniforms and up to 500 lilangeni $(\$ 56)$ in tuition fees.

"This is too much for the unemployed. So there are all these kids with nothing to do. They get into trouble or become victims of crime," says 
Ntombikayise Nyoni, legal officer at the Swaziland Action Group Against Abuse (SWAGAA), which is sponsored by Crossroads Canada (www.osisa .org/open-learning/education/swaziland /youth-and-adult-learning-and-education -swaziland).

Data indicate that the high school fees have become a barrier to education. Illiteracy among those aged 15 and over is $13 \%$, according to UNICEF (www.unicef.org/swaziland /sz_publications_2007violenceagainst children.pdf). An estimated $9.4 \%$ of primary school-age children do not attend school. Lack of funding was the main reason that $18 \%$ of girls aged $13-17 \mathrm{did}$ not attend school. The next most common reason? Pregnancy (17\%).

Abuse is as systemic a problem. An estimated one in three girls experience sexual violence, while one in four experience physical violence, according to a joint report from the United States Centers for Disease Control and Prevention and the Swaziland United Nations Children's Fund (www.unicef .org/swaziland/sz_publications_2007 violenceagainstchildren.pdf). Roughly $27 \%$ of those physically abused children require the attention of a physician. Meanwhile, nearly 3 in 10 children experience emotional abuse.

Among children who were sexually abused, about $5 \%$ had forced intercourse and $9 \%$ had coerced intercourse. More than half of all sexual abuse is not reported and victims seek help in fewer than one in seven incidents largely because they aren't aware that what they experienced was abuse, or because they feared being abandoned, the report states. "Preventing violence against children in Swaziland is complicated by the influence of poverty and social changes that increase the vulnerability of children (e.g., high rates of HIV/AIDS, increasing number of orphans)."
SWAGAA believes there is "significant" under-reporting of sexual abuse cases (www.swagaa.org.sz/wp-content /uploads/2012/02/2011-2012-Care-and -Support-Data-Analysis-Brief.pdf). Of 247 child abuse cases reported to the association in fiscal 2011/12, 91 involved sexual abuse. Age-wise, the majority of those, 37 cases, involved children aged 10-14. There were 13 sexual abuse cases involving children aged 0-5, 22 involving those aged 6-9, and 19 involving youths aged 15-17.

For the better part of two decades, SWAGAA has advocated for law reform, particularly in the form of a sex offense and domestic violence bill. Such a bill was finally passed in the legislative assembly in October 2011, and is now awaiting Senate approval, basically a nod from King Mswati III.

Nyoni says the legislation expands the definition of rape, varies the duration of prison sentences according to the nature of the assault and establishes a sex offender's registry. It also updates Swazi legislation and recognizes international conventions, Nyoni adds. The country now uses the 1920 Girl's and Women's Protection Act as the basis for jurisprudence. "When you have laws that are outdated it's difficult to reach maximum justice."

Other recent legislative advances include the September 2012, passage of the Child Welfare Act, which prohibits sex with a child under age 16 .

When combined with progress in reducing mother-to-child transmission of HIV, the legislative advances offer a glimmer of hope for the future. According to a July 2012, UNAIDS report, the number of new pediatric cases of HIV fell 39\% between 2009 and 2011, while the percentage of under-five deaths caused by HIV dropped from $30 \%$ to $23 \%$ (www .unaids.org/en/media/unaids/content assets/documents/epidemiology/2012 /JC2296_UNAIDS_TogetherReport_2012 _en_em.pdf).

Or as Nyoni notes, "much as there are problems, some of the changes bring hope." - Barbara Sibbald, CMAJ

CMAJ 2013. DOI:10.1503/cmaj.109-4404

Editor's note: Last of a multipart series. Barbara Sibbald's accommodation and transportation while in Swaziland were provided by Médecins sans Frontières.

Part I: Making sense of the world's highest HIV rate

(www.cmaj.ca/lookup/doi/10.1503/cmaj.109-4315).

Part II: The face of an epidemic (www.cmaj.ca/lookup/doi/10.1503/cmaj.109-4320).

Part III: Responding to Swaziland's dual epidemic

(www.cmaj.ca/lookup/doi/10.1503/cmaj.109-4334).

Part IV: New diagnostics, available care offer hope to patients with drug-resistant tuberculosis (www.cmaj.ca/lookup/doi/10.1503/cmaj.109-4341).

Part V: “I never gave up hope” (www.cmaj.ca/lookup/doi/10.1503/cmaj.109-4369).

Part VI: Cultural and societal obstacles in responding to Swaziland's HIV epidemic (www.cmaj.ca/lookup/doi/10.1503/cmaj.109-4396).

For other patient stories, the TB \& Me website features a collection of blogs written by people living with MDR-TB in different parts of the world (http://blogs.msf.org/tb/). 